\title{
Brain Asymmetry of Structure and/or Function
}

\author{
Lesley J. Rogers \\ School of Science and Technology, University of New England, Armidale, NSW 2351, Australia; \\ lrogers@une.edu.au
}

Received: 31 January 2019; Accepted: 31 January 2019; Published: 13 February 2019

This book contains submissions to a Special Issue of Symmetry on the topic of brain asymmetry in humans (4 papers) and non-humans (7 papers). Whereas asymmetry of the human brain has been known for well over a hundred years [1], the first evidence of functional asymmetry of the brain in non-human species is a relatively recent discovery [1,2]. Until the reports of lateralization in birds and rodents in the 1970s and 1980s, brain asymmetry was seen as limited to humans and, hence, a hallmark of human superiority over all other species. There is now ample evidence of the fallacy of that idea, and this discovery has stimulated research on the mechanisms, development, evolution and function of brain asymmetry. A number of papers in this Special Issue provide further evidence of brain asymmetry in reptiles, birds, mammals and even in an invertebrate species (bees). The various topics include asymmetry of response to visual, auditory, olfactory and magnetic stimuli. Mechanisms and structures involved in asymmetry are covered, as well as development and genetic aspects of expressed asymmetry.

Conflicts of Interest: The author declares no conflict of interest.

\section{References}

1. Ocklenburg, S.; Güntürkün, O. The Lateralized Brain: The Neuroscience and Evolution of Hemispheric Asymmetries; Academic Press; Elsevier: London, UK, 2018.

2. Rogers, L.J.; Vallortigara, G.; Andrew, R.J. Divided Brains: The Biology and Behaviour of Brain Asymmetries; Cambridge University Press: Cambridge, UK, 2013.

(C) 2019 by the author. Licensee MDPI, Basel, Switzerland. This article is an open access article distributed under the terms and conditions of the Creative Commons Attribution (CC BY) license (http:/ / creativecommons.org/licenses/by/4.0/). 